\title{
Study of the Compensation for Cultural Filtration in the Translation of Yu Xuanji's Poems
}

\author{
Xie Mengling ${ }^{1,2}, \mathrm{Lu} \mathrm{Jie}^{1 \text {,* }^{*}}$ \\ ${ }^{1}$ Foreign Language College, Chengdu University of Information Technology, China \\ ${ }^{2}$ College of Marxism, Northwest Normal University, China
}

Copyright@2019 by authors, all rights reserved. Authors agree that this article remains permanently open access under the terms of the Creative Commons Attribution License 4.0 International License

\begin{abstract}
Yu Xuanji's Poems were translated into the Anglophone World by Jeanne Larsen, Kenneth Rexroth and Ling Chung, Kang-i Sun Chang and Haun Saussy, Justin Hill and Genevieve Wimsatt. This essay mainly focuses on cultural filtration and compensation strategies in these translated versions. Inadequate understanding is the main cause for cultural filtration. This essay analyzes inadequate understanding for Chinese literary tradition, Chinese culture, Chinese language and Chinese ancient society. Translation of literal meaning with notes, translation of implicated meaning with notes, juxtaposition of implicated meaning and literal meaning and paraphrase embedded in text were adopted by these translators to compensate the cultural filtration. The research on the cultural filtration and compensation strategies in these translated versions helps translators to recognize that knowing Chinese culture and Anglophone culture adequately and taking appropriate compensation ways are crucial for the translation of Yu Xuanji’s poems.
\end{abstract}

Keywords Cultural Filtration, Compensation, Yu Xuanji’s Poetry, Translation

\section{Introduction}

Yu Xuanji (844-871) is one of the four great female poets in the Tang Dynasty(618-907) and her 50 poems are included in the Complete Tang Poems(《全唐诗》). Most of her poems are translated into Anglophone World: 7 by Jeanne Larsen, 4 by Kenneth Rexroth and Ling Chung, 18 by Haun Saussy and Kang-i Sun Chang, 28 by Justin Hill and 43 by Genevieve Wimsatt.

Poetry translation is not only the simple transformation of one language to others as cultural filtration is inevitable, it also needs translators' commanding of intercultural communication ability to fully and accurately show the poetry to target readers. So they are confronted with an enormous challenge--how to compensate cultural filtration.
Shunqing Cao once said in The Variation Theory of Comparative Literature: "Cultural filtering is the selection, transplantation, transformation, and reconstruction of communicating information by receivers according to their cultural tradition, realistic context, value standard, and aesthetic habits, whose result is the variation of the original communicating information within an indigenous context"[1]. Cultural filtration is the prerequisite when translations enter the target culture and if they don't go through cultural filtration, they would not be really accepted by target culture. Translation of Yu Xuanji's poems is an embodiment of the exchange of Chinese and Anglophone cultures. These translated versions mentioned above adopted different ways to compensate cultural filtration.

\section{Cultural Filtration in Translation of Yu Xuanji's Poems}

Translator's inadequate understanding for Chinese literary tradition, for Chinese culture, for Chinese language and for Chinese ancient society causes cultural filtration when Yu's poems are translated into the Anglophone world.

\subsection{Cultural Filtration Caused by Inadequate Understanding for Chinese Literary Tradition}

With translators' varying degrees of understanding for Chinese literary tradition, the degrees of cultural filtration in their translation vary. One of the conspicuous example is symbol as it symbolizes different meaning in different literary tradition.

From Wikipedia "A symbol is an object that represents, stands for, or suggests an idea, visual image, belief, action, or material entity." In short, symbol is used to express some abstract meanings by specific objects. But in different literary tradition, these concrete things have different symbolic meanings even without symbolic 
meaning, so it causes difficulties to accurate translation. There are numerous symbols in Yu Xuanji's poems which are translated by translators in Anglophone world with different compensation strategies under cultural filtration.

In “Sending spring love to TZU-AN”(《春情寄子安》), “如松匪石盟常在, 比翼连襟会肯迟” contains symbols. Peng, Zhixian, and Zhang Yi summarized that in Chinese literary tradition, “如松” symbolizes faithful love which can be found in books such as "the Book of Odes"(《诗 经》) and “the Book of Rites”( 《礼记》). “匪石” means that their steadfast love which can not be changed in Chinese literary tradition. In "the Book of Odes", it is "My heart isn't a stone and no one can change it” (我心匪石, 不可 转也) [2].

Mrs. Wimsatt translated it as "Our vows were of the greenness of the pine, of the rock's steadfastness; Sometimes even the One-Winged Birds remain too long as Twain.”[3] Obviously, Mrs. Wimsatt misunderstood the meaning of “匪石” in Chinese literary tradition and she just thought “石” was the symbol of steadfastness but she didn't learn that “匪” can mean "not” in Chinese literary tradition and she ignored “匪”. Although her translation expressed the same meaning of the original poem, it misled her readers to believe “石” symbolizes steadfast love rather than “匪石”.

Also, Justin Hill didn't realize that “匪石” meant unswerving love rather than “石” and just omitted the word "not". He translated it as "We're like the pine and crag that endure many winters together."[4] He used liberal translation to give readers more concrete feelings and added story to the the original line. It is a way that compensates cultural filtration in translation of this verse but it doesn’t convey the symbolic meaning of “如松” and “匪石” in Chinese literary tradition.

Differently, in The Orchid Boat: Women Poets of China by Kenneth Rexroth and Ling Chung, the translation of “如 松 匪石盟常在” is “Steady as a pine, not like a rolling stone, My oath of love is forever." [5] The translators knew the symbolic meaning of “如松” and “匪石” clearly in Chinese literary tradition. But when the line was introduced to Anglophone world, it must go through cultural filtration and people in the Anglophone world may not got the point, so the translator showed the symbolic meaning of “如松” and “匪石” by using literal meaning and connotation together, adding "steady" to modify "pine" and using "rolling" to embellish "stone" so readers can comprehend poet's intention of using “如松” and “非石” in this line.

Likewise, in Women Writers of Traditional China: An Anthology of Poetry and Criticism by Kang-i Sun Chang and Haun Saussy, the translators learned the symbolic meaning of “如松” and “非石” in Chinese literary tradition exactly. The translation is "I am like pine-I am no stone-my oath will always endure." [6]As Chinese, it is lucid but for the translation, readers in the Anglophone world may be confused on the connection between "pine" or "no stone" and "my oath will always endure". So under the poem, there is a note "Poem 26 of the Book of Odes was reputedly composed by a young widow who refused to obey her family's demand that she remarry: 'My heart is not a stone; you cannot roll it about,' she protests"[6]. Literal translation with note, as a method of cultural filtration compensation, is beneficial for readers in the Anglophone world to learn "no stone" can be as a token of never changing love.

\subsection{Cultural Filtration Caused by Inadequate Understanding for Chinese Culture}

Yu Xuanji's poems abound with allusions, metaphors and antithesis, and she is adept in polishing words and meanings. All of these cause difficulties for translators in the Anglophone world to interpret her poems accurately. Undoubtedly, translators' abilities vary from person to person and they possess different levels of knowledge about Chinese culture. Especially, some of Yu's poems are influenced by Taoism, which is the only native religion in China. When they translate Yu's poems and make compensations under cultural filtration, their understandings for Chinese culture are crucial.

In “Living in the Summer Mountains”(《夏日山居》), “移得仙居此地来” means the poetess moved to the dwelling in mountain. “仙居” refers to the place where Taoist gods live, but in this line it represents Yu' own dwelling. In Chinese culture, firstly, “仙” refers to the supernatural being who possesses special ability and is immortal in myth like the goddess Nvwa. Secondly, “仙” refers to the people who have excellent ability as Li Bai is known as “Poetic Genius”(诗仙). Besides, “仙” is the euphemism of death. Nature, goodness, absolute freedom and immortality are characters of “神仙” in Taoist culture, and we can become “神仙” by Taoist practice.

Mrs. Wimsatt translated it as "From Earth removed to Genii Land!”[3] She knew “仙居” referred to Yu's own home so she compensated the cultural filtration by literal translation with note, and the note was "Genii Land impressed the immigrant during earlier stretches of her sojourn there”[3]. But she didn’t understand “仙居” was the residence of gods in Chinese Taoism and she did not have a correct knowledge about Chinese “仙” so she translated it as "Genii". But "Genii” means "supernatural creatures in Arab folklore and Islamic teachings" or "guardian spirits in roman mythology"[7]. And there, the translator changed the respectable gods who represent nicety to the evil spirits or their servants. It was the misinterpretation of “仙” in Chinese culture and it caused misreading among recipients and may confuse recipients why the poetess selected this place to settle down in.

Justin Hill[4] interpreted it as "I've moved up here to live where the gods could live”, he realized that “仙居” was Yu's home and it was as good as the place where gods live. He not only interpreted the literal meaning of “仙居” 
but also added the connotation. The translation well kept the original elements and made compensation under the cultural filtration of introducing it to the Anglophone world. Also, Jenny Larsen comprehended it fully and the way of compensation for cultural filtration was same as Justin Hill. The translation was "this ground is where I've come to: a place gods might call home" [8], both the literal meaning and the implicit meaning were included to the alien civilization.

\subsection{Cultural Filtration Caused by Inadequate Understanding for Chinese Language}

In “despondent Thoughts” (《秋怨》), the line “洞房偏 与更声近” has a word that means differently with its common meaning. “洞房” is polysemous. Its original meaning is the profound inner room and always refers to bedroom and boudoir. Wang Mi summarized that it only represented aristocratic luxurious residences in Han Dynasty [9]. One of its extended meaning was demic acupuncture point in Taoist regimen which appeared in the South and North Dynasty. In Tang Dynasty, there were a variety of meanings of “洞房” such as the place for sex in most erotic poems, and nuptial room, and Taoist priests' or monks' living place. Nowadays nuptial room has been the common meaning of “洞房”. Although it already had the meaning of nuptial room in Tang Dynasty, considering Yu Xuanji's Taoist belief, the poetess expressed sadness and solitude in the Taoist priests' room which looked like a cave.

Mrs. Wimsatt translated it as "bridal room"[3] and Justin Hill's translation was "the bridal chamber"[4]. Both Justin Hill and Mrs. Wimsatt misunderstood “洞房”, they just knew its common meaning- "nuptial room", and they didn't learn its original meaning as "the profound chamber", let alone understanding the poetess' intention. English readers may have a wrong understanding of the line after reading their translations due to their mistaken understanding. Fortunately, Jeanne Larsen[8] knew “洞房” referred to Yu's bedroom and she translated it as "my room like a cave". She compensated cultural filtration when introduced it to the Westen world by juxtaposing the literal meaning "room like a cave" and hidden meaning "my room”.

In "Visiting CH'UNG Chen Kuang and Seeing in the South Hall the Table Where Graduates Inscribe Their Names”(《游崇真观南楼睹新及第题名处》), the line “历 历银钩指下生” covers a polysemy “银钩”. The first meaning is the silver hook, the second meaning is a kind of silver jewelry of women, the third is metaphor meaning of beautiful and vigorous calligraphy, and finally is the metaphor meaning of crescent moon. This line uses its metaphor meaning of beautiful and vigorous calligraphy. So if it is just translated as "silver hooks", recipients in the western world will be confused as it has not the metaphor meaning in western tradition.
Mrs. Wimsatt translated the verse as "Fine, fine these skill-born inscriptions shine" [3] and added a note, part of it is "Silver Hooks, a term applied to elegantly written Chinese characters”[3]. Mrs. Wimsatt didn't just translate “银钩” as “silver hooks” and she used “ skill-born inscriptions" as well as gave a note so it is easy for recipients to learn the metaphor meaning of “银钩” in Chinese culture.

In Women Writers of Traditional China: An Anthology of Poetry and Criticism, the interpretation of “银钩” was "silver hooks"[6], at the same time, a note was given, 'Silver hooks' here represents the writing of the successful candidates”[6]. The literal translation of “银钩” is unfaithful to Chinese culture and the note is unhelpful for Anglophone readers.

In another translated works, The Orchid Boat: Women Poets of China, Kenneth Rexroth and Ling Chung[5] adopted a different way to deal with this line. This line was interpreted as "Their names are written in beautiful characters And posted in order of merit", the translators adopted the implication instead of literal meaning. This translation did express the meaning of this line and recipients got it immediately when they read it, but Chinese's special metaphor of comparing beautiful calligraphy to silver hook disappeared in this translation.

\subsection{Cultural Filtration Caused by Inadequate Understanding for Chinese Ancient Society}

Culture is the product of era. Poetry always embodies a certain social backgrounds. The meaning of many images can be understood only when people stand in their specific society. And in different society, their meanings may change and these imagoes even not exist in some societies. So when Yu's poems are translated to the Anglophone world, cultural filtration is inevitable. And their translations are uneven as translators' understanding levels for Chinese ancient society are different.

In "Divided by the Han River Sent to Li TZU-AN" (《隔 汉江寄子安》), the line “况听家家远砧” contains an imago which exists in special social background with abundant emotions. It is the sound of “砧”.“砧” is a smooth slate. In ancient China, Women put dirty clothes on the "smooth slates" and use sticks to strike in the night of autumn [10]. People will associate with joy of family reunion and couples' harmony as well as grief of parting if they listen to the sound of “砧”.It is to convey grief of parting in this poem.

Justin Hill translated it as "We remember soft words and quiet moments as we leave each other behind"[4] . Liberal translation was used to compensate under the cultural Filtration in interpreting this line. Although the interpretation was really concise, it did express the meaning of this line with flexibility. But the translation filtered out the Chinese traditional imago, and horned the aesthetic perception. It is regrettable. 
Mrs. Wimsatt translated it as "Listen! In home upon home the washing paddles resound!” [3] She used literal translation with sentences to explain it. It is "The thud of washing paddles wielded by wives preparing their husbands' winter clothing by beating garments on the washing stones by the stream... A homely, humdrum sound, but one which grated on the lonely heart"[3]. Mrs. Wimsatt knows the sound of “砧” in Chinese ancient society well and spreads it to the Anglophone readers. And the interpretation did show the affective meaning and connotative meaning of “况听家家远砧” to English readers.

\section{Compensations for Cultural Filtration in Translation of $\mathrm{Yu}$ Xuanji's Poems}

Adopting what's kind of compensation to make up for cultural filtration is crucial when Yu's poetry is interpreted to the Anglophone world. In terms of cultural filtration compensation, this essay mainly studies translation of literal meaning with notes, translation of implicated meaning with notes, juxtaposition of implicated meaning and literal meaning and paraphrase embedded in text.

\subsection{Translation of Literal Meaning with Notes}

Translation of literal meaning with notes refers to translators adding explanatory annotation which often use intratextual annotation and footnote after literal translation.

According to Wikipedia, "Literal translation, direct translation, or word-for-word translation is the rendering of text from one language to another one word at a time with or without conveying the sense of the original whole.” In “Deeply Moved, I Send This to Someone”(《感怀寄人》), the original poem “未起惠兰心” was translated as “Would not give rise to an orchid heart” by Haun Saussy and Kang-i Sun Chang[6]. “惠兰心” was literally translated as "an orchid heart”. This literal translation is beneficial for keeping the original poems' conciseness and the cultural image-an orchid heart, but causes difficulties for Anglophone readers to understand it as cultural filtration caused by different cultures. Haun Saussy and Kang-i Sun Chang compensated the cultural filtration by giving a note: "The orchid, by allusion to the "Li sao" of Qu Yuan (see p.37), signifies an upright and virtuous mind"[6]. So, adding notes can solve the problem by offering cultural images' origin, connotation and other information about them.

Chinese poems are different with those of Anglophone world. From Jauss' s “horizon of expectations”, translation of literal meaning with notes is beyond Anglophone readers' expectation horizons and can arouse their interests to go on reading and finally update their expectation horizons[11]. So this compensation strategy enriches Anglophone poetry's forms and connotations. And it shows a new world to Anglophone readers. It can effectively deliver cultural images contained in poems. So if the Chinese poem contains cultural images which have profound cultural connotation, this can be a good way to disseminate Chinese culture.

\subsection{Translation of Implicated Meaning with Notes}

Under the cultural filtration of translation, translators sometimes translate implicated meaning of cultural images. In “Spring Feelings, Sent to Zi’an”(《春情寄子安》), “比 翼连襟会肯迟” was translated as “Like paired-wing birds or two robes joined, how could I want to delay our meeting?” by Haun Saussy and Kang-i Sun Chang[6]. They translated “比翼” as “paired-wing birds” rather than "biyi birds" so they conveyed the meaning of biyi birds by the word "paired". But although this way can express the meaning of the cultural image "biyi birds" to readers and make readers have a correct understanding but filtered out the Chinese feature - biyi birds. So they offered a note to show the Chinese culture about "biyi birds" to compensate the cultural filtration. The note is "The biyi, a legendary bird, had only one wing and could not fly without a mate. Like 'two robes joined', it became a symbol of conjugal felicity" [6].

Translation of implicated meaning with notes makes the poem easier to understand and to accept by Anglophone readers. Also, it gives translators more freedom to translate these cultural images. But this strategy needs translators' high command of Chinese culture and Anglophone culture.

\subsection{Juxtaposition of Implicated Meaning and Literal Meaning}

Translators need to pay much attention to how to convey poetic meaning as well as keep poetic features. Juxtaposition of implicated meaning and literal meaning is a good way. For example, the mentioned Kenneth Rexroth and Ling Chung's translation of “如松”. The translation is "Steady as a pine”, which translated the literal meaning "as a pine" as well as the implicated meaning "steady". It not only remains the cultural image "as a pine" but also conveys its symbolic meaning without notes. At the same time, it shows the connection of the cultural image and its implication, so it stimulates Anglophone readers to consider the connection.

On the one hand, from Ren Xiu and Qiu Wangsheng, this strategy can reduce Anglophone readers' strange sense and sense of alienation as using corresponding Anglophone words to translate and show implicated meaning [12]. Although these cultural images may have corresponding Anglophone words, only these words cannot express their own implications in Chinese culture. So on the other hand, juxtaposition of implicated meaning and literal meaning can propagate Chinese unique culture.

This way makes up for cultural filtration well when translating Yu's poems and applies for the cultural images 
that are used frequently and easy for Anglophone readers to receive.

\subsection{Paraphrase Embedded in Text}

As a noun, paraphrase is "a statement that expresses sth that sb has written or said using different words, especially in order to make it easier to understand" [13] in Oxford Advanced Learner's English-Chinese Dictionary. Chinese culture is different with Anglophone culture so when Yu' poems are translated to Anglophone world, cultural filtration is inevitable and paraphrase embedded in test is an effective compensation way. It was largely used by Mrs. Wimsatt in Selling Wilted Peonies: Biography and Songs of Yu Hsuan-Chi and Justin Hill in Passing Under Heaven.

It embeds the explanation in the novel and biography in Yu's translation. Whatever under literal translation or liberal translation, paraphrase keeps the poetry's conciseness, spreads Chinese culture, enriches the novel and biography's connotations and renders readers easy access to understand Yu's poems.

\section{Conclusions}

Most of Yu Xuanji's poems were translated into the Anglophone world under cultural filtration which mainly caused by inadequate understanding. This essay has analyzed on inadequate understanding for Chinese literary tradition, Chinese culture, Chinese language and Chinese ancient society. Translators need to reconcile Chinese features and Anglophone features in translation. And they provided diverse compensation ways such as translation of literal meaning with notes, translation of implicated meaning with notes, juxtaposition of implicated meaning and literal meaning and paraphrase embedded in text. Every compensation strategy has its superiority. Translation of literal meaning with notes can keep the original poem's conciseness as well as disseminate Chinese culture well. Translation of implicated meaning with notes allows translators translate cultural images more freely and not lose them. Juxtaposition of implicated meaning and literal meaning can inspire recipients to consider the connection between cultural images and their implicated meaning. Paraphrase embedded in text is easier for readers to understand and enriches the text's contents. Researching these translated versions' cultural filtration and compensation ways has significant meaning for better disseminating Chinese culture in the background of Chinese culture's "going out" and better knowing the cultural peculiarity in Anglophone world.

\section{Acknowledgements}

This essay is an achievement of the project "The Dissemination and Influence of Tang Taoist Poets in
Anglophone World" (Postdoctoral Number 217905) supported by China postdoctoral science foundation and the project of "The Oversea Dissemination of Xue Tao's Poetry from a Crosscultural Perspective" supported by Sichuan Social Science Association(SC18WY008). I am grateful to the fund to enable me to make research for this project.

\section{REFERENCES}

[1] S. Q. Cao. The Variation Theory of Comparative Literature, Springer-Verlag Berlin Heidelberg Press, New York, 2013.

[2] Z. X. Peng, Y. Zhang. Annotations of Yu Xuanji’s Poems in Chronological Order, Xinjiang University Press, Xinjiang, 1993.

[3] W. Genevieve. Selling Wilted Peonies: Biography and Songs of Yu Hsuan-Chi, Columbia University Press, New York, 1936.

[4] J. Hill. Passing Under Heaven, Great Britain, London, 2004.

[5] K. Rexroth, C. Ling. The Orchid Boat. Women Poets of China, New Directions Publishing Corporation, New York, 1982.

[6] K. C. Sun, H. Saussy. Women Writers of Traditional China: An Anthology of Poetry and Criticism, Stanford University Press, California, 1999.

[7] J. Lu. The Inevitability and Roots of Variation in Literature Translation--from the English Version of Xue Tao's Poetry by Genevieve Wimsatt, 5th Annual International Conference on Language, Literature and Linguistics, 201, 2016.

[8] J. Larsen. Willow, Wine, Mirror, Moon: Women's Poems from Tang China, BOA Editions Ltd, New York, 2005.

[9] M. Wang. Exploration on Semantic Change of the world-“Bridal Chamber”, Comparative Study of Cultural Innovation, No.19, 75-76.

[10] Q. Xiang. Expatiation on Pound Clothing Sound in Autumn Night--Exploration on the image-Pound Clothing Sound, Journal of Chinese Reference Middle School, No.21, 71-72.

[11] C. M. Huang. The Advantages of Literal Translation of Chinese Ancient Poetry under horizon of expectations, Journal of Inner Mongolia Agricultural University(Social Science Edition), Vol.10, No.4, 371-372, 375.

[12] X. Ren, W. S. Qiu. Integration of Domestication and Foreignization Strategies to Communicate Cross -Cultural Factors in Translating, Journal of Chengdu Textile College, Vol.23, No.3, 44-46.

[13] G. S. Lu. Oxford Advanced Learner's English-Chinese Dictionary, The Commercial Press, Beijing, 2014. 